\title{
Synthesis and Characterization New Polyurethane Membrane From Hydroxylated Rubber Seed Oil
}

\author{
MARLINA $^{1 *}$, SAIFUL ${ }^{1}$, RAHMI $^{1}$, SITTI SALEHA ${ }^{1}$ and SALFAUQI NURMAN ${ }^{2}$ \\ ${ }^{1}$ Chemistry Department of Mathematics and Sciences Faculty, \\ Syiah Kuala University, Banda Aceh, Indonesia. \\ ${ }^{2}$ Agriculture Industrial Technology Department of Agriculture Technology Faculty, \\ Serambi Mekkah University, Banda Aceh, Indonesia. \\ ${ }^{*}$ Corresponding author E-mail : marlina_rachman@yahoo.com
}

http://dx.doi.org/10.13005/ojc/330122

(Received: November 10, 2016; Accepted: January 01, 2017)

\begin{abstract}
New polyurethane membrane from hydroxylated rubber seed oil has been prepared in this study. Hydroxylated process of rubber seed oil improved $135.30 \%$ of hydroxyl number and decreased $73.91 \%$ of iodine number of rubber seed oil. Optimum polyurethane membrane was obtained at the composition of hydroxylated rubber seed oil:hexamethylene-1,6-diisocyanate was 5:7 v/w. The membrane was homogeneous, dry, smooth, slightly stiff and brownish yellow. The clean water flux and rejection factor of the membrane were $0,544 \mathrm{~L} / \mathrm{m}^{2}$.h.bar and $98.86 \%$, respectively. FTIR spectra indicated the formation of urethane bond $\left(\mathrm{N}-\mathrm{H}\right.$ at $\left.3308 \mathrm{~cm}^{-1}\right)$. Thermal analysis showed two stages of decomposition at $223^{\circ} \mathrm{C}$ and $386^{\circ} \mathrm{C}$. The membrane exhibited a strong and elastic properties with a tensile strength of $1.13 \mathrm{kgf} / \mathrm{mm}^{2}$ and elongation $215.36 \%$.
\end{abstract}

Keywords: Rubber seed oil, Hexamethylene-1,6-diisocyanate, Synthesis, Polyurethane membrane, Characterization.

\section{INTRODUCTION}

Indonesia is an agricultural country which has a wide range of biological, one of them is rubber plant (Heveabrasiliensis) ${ }^{1}$. The products of rubber plant are only put emphasis on the processing of latex and trunks, while other products such as its seed has not received more attention. Rubber seeds are the by products of rubber plantations which can be utilized for biodiesel ${ }^{2,3}$. To improve the diversification of plant products, an effort is needed to increase the added value of these plants.

Rubber seed contains $40.76 \%(\mathrm{w} / \mathrm{w})$ of oil. Rubber seed oil contains $38.59 \%$ of oleic acid, $41.06 \%$ of linoleic acid, $10.43 \%$ of stearic acid and $9.92 \%$ of palmitic acid. Rubber seed oil has a hydroxy number $40.33 \mathrm{mgKOH} / \mathrm{g}$ and $154.05 \mathrm{gl}_{2} / \mathrm{g}$ of iodine number ${ }^{4}$. Rubber seed oil has a color (lovinbond) $22 \mathrm{R} ; 23,2 \mathrm{Y}, 0.916$ of specific gravity $\left(30^{\circ} \mathrm{C}\right), 43.62$ 
$\mathrm{mg} \mathrm{KOH} / \mathrm{g}$ of acid number, free fatty acids 21.4 , $202.91 \mathrm{mg} \mathrm{KOH} / \mathrm{g}$ saponification number and 136.21 $\mathrm{g} \mathrm{I}_{2} / 100 \mathrm{~g}$ of iodine numbers ${ }^{5}$.

Hydroxylation process is the addition of a hydroxy group into a compound by performing addition -OH group to the double bond ${ }^{6}$. The reaction takes place in two stages, where the first stage is protonated alkene to produce a carbocation. The second stage is nucleophilic addition to the carbocation. Both of reactions take place according to Markovnikov rule. Hydroxylation process in vegetable oils can increase the concentration of hydroxyl ${ }^{6}$.

In our previous research, polyurethane membranes have been prepared by using vegetable oil. The free fatty acids and oxidized fatty acids of castor oil were used as a source of hydroxyl and 2,4-toluene diisocyanate (TDI) as the source of isocyanate ${ }^{7}$. polyurethane membrane of rubber seed oil with HMDI had been synthesized, the resulting membrane has a homogeneous, dry, elastic, brownish yellow, wavy with the flux and rejection factor were $0544 \mathrm{~L} / \mathrm{m}^{2}$.h.bar and of $100 \%$, respectively ${ }^{4}$. Therefore, in this study hydroxylated rubber seed oil and hexamethylene-1,6-diisocyanate (HMDI) were used for polyurethane membrane preparation.

\section{MATERIALS AND METHODS}

\section{Materials}

The raw material was rubber seed taken from the plantation residents in the village Gunong Kleng, Meureubo, West Aceh, Aceh Province, Indonesia. Chemicals used were hexamethylene1,6-diisocyanate (HMDI) purchased from Merck, chloroform, acetic acid, $\mathrm{KOH}, \mathrm{KI}, \mathrm{Na}_{2} \mathrm{~S}_{2} \mathrm{O}_{3}$, starch indicator, n-hexane, $\mathrm{NaCl}, \mathrm{H}_{2} \mathrm{SO}_{4}$, and methanol were purchased from Sigma-Aldrich.

\section{Instrumentation}

FTIR spectra of rubber seed oil and polyurethane membrane used (Agilent resolution pro cary 630 FTIR spectrometer), membrane morphology viewed using SEM (Tabletop microscope 3000 ), thermal analysis of polyurethane membrane using TGA and DTA (SDT Q600) and mechanical strength of the membrane was tested with (Control computer series $10-100 \mathrm{KN}$ )

\section{Rubber seed oil extraction process}

Rubber seeds were cleaned, peeled, dried at room temperature and crushed into powder. Rubber oil extraction was carried out by $n$-hexane at $80^{\circ} \mathrm{C}$ for 4 hours. A rotary evaporator was used to separate the rubber seed oil and n-hexane at $60^{\circ} \mathrm{C}$ for 30 minutes.

\section{Hydroxylation process of rubber seed oil}

$25 \mathrm{~mL}$ of rubber seed oil was added to 2.5 $\mathrm{mL}$ of $\mathrm{H}_{2} \mathrm{SO}_{4} 35 \%$, then stirred for 90 minutes, and then chloroform was added to separate the remaining water phase. 5 grams of anhydrous $\mathrm{Na}_{2} \mathrm{SO}_{4}$ was added to the organic phase and then filtered. The filtrate obtained was evaporated using a rotary evaporator and the oil obtained was characterized.

\section{Preparation of polyurethane membrane}

$5 \mathrm{~mL}$ of hydroxylated rubber seed oil and 1,6-hexamethylene diisocyanate (with a series of composition) were mixtured by using a magnetic stirrer at a temperature of $90-100^{\circ} \mathrm{C}$ for $60 \mathrm{~min}$. Then poured in a petri dish, cured an oven at a temperature of $115-120^{\circ} \mathrm{C}$ for 8 hours. Once the membrane had been formed, then the membrane was released in the flowing water with the aid of a spatula.

\section{RESULT AND DISCUSSION}

\section{Characterization of hydroxylated rubber seed oil}

Hydroxylation process of rubber seed oil was conducted by using water in acidic solutions. $\mathrm{H}^{+}$as a catalyst break the double bond of rubber seed oil resulting in the addition reaction with $-\mathrm{OH}$ groups from water. The proposed of addition reaction of linoleic acid can be seen in Fig 1.

Hydroxylated rubber seed oil has a hydroxyl number $94,903 \mathrm{mgKOH} / \mathrm{g}$ and iodine number 40.185 $\mathrm{g} \mathrm{I}_{2} / \mathrm{g}$. There was an increase for the hydroxyl number and a decrease in iodine number of $40.333 \mathrm{mgKOH} / \mathrm{g}$ and $154.052 \mathrm{~g} \mathrm{I}_{2} / \mathrm{g}^{4}$. Hydroxylation process had improved hydroxyl number amount up to $135.30 \%$.

FTIR spectra of rubber seed oil and hydroxylated rubber seed oil are shown in Fig 2. The -OH groups of hydroxylated rubber seed oil at wave number $3400 \mathrm{~cm}^{-1}$ was appear broader comparing to the spectrum of rubber seed oil. Peak of $-\mathrm{CH}$ alkene 
bond at wave number $3010 \mathrm{~cm}^{-1}$ in the spectrum of rubber seed oil seems clearer with high intensity comparing the spectrum of hydroxylated rubber seed oil. It shows that the hydroxylation process of rubber seed oil has reduced the number of double bonds and those results also supported by reduction of iodine number.

\section{Polyurethane membrane preparation}

The preparation of a polyurethane membrane from hydroxylated rubber seed oil and hexamethylene-1,6-diisocyanate through addition reaction can be seen in Fig 3. The visual results of the membrane with HMDI composition is shown in Table 1.

Table 1 shows the visual of polyurethane membrane with composition variation of HMDI. The optimum composition of hydroxylated rubber seed oil and HMDI was 5: $7 \mathrm{v} / \mathrm{w}$ with a polymerization temperature of $90-100^{\circ} \mathrm{C}$ and a curing temperature of $115-120^{\circ} \mathrm{C}$. It showed better results than the other variations. The obtained polyurethane membrane was homogeneous, smooth, dry (not greasy), a little rigid and brownish yellow.

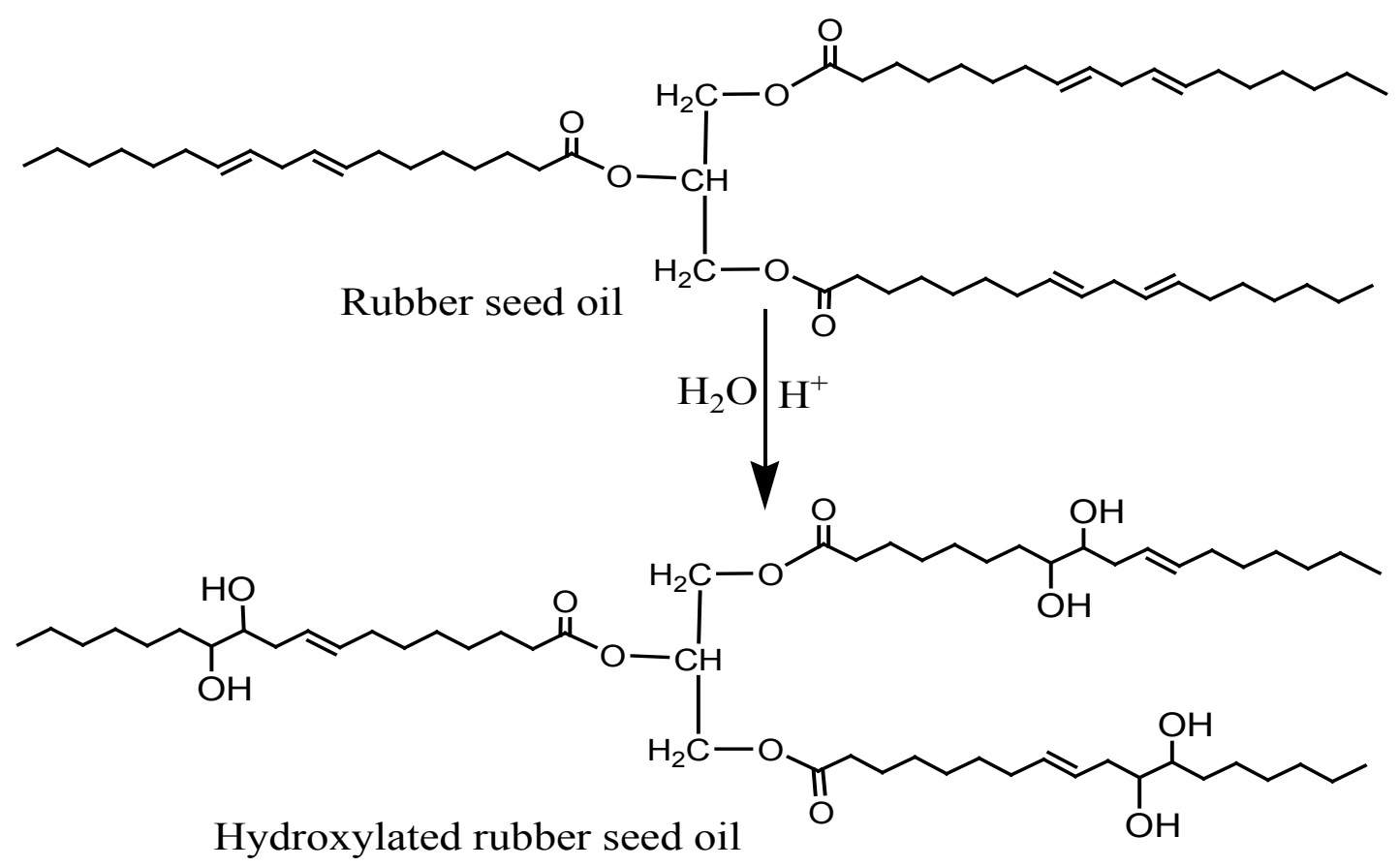

Fig. 1: The Proposed of addition reaction

Table 1: Variations in composition in the preparation of polyurethane membrane

\begin{tabular}{ccl}
\hline HRSO $^{\text {(ml) }}$ & HMDI $^{2}$ (grams) & Visual descriptionpolyurethane membrane \\
\hline 5 & 4 & homogeneous, dry, slightly elastic, yellow, slightly bubbly \\
5 & 5 & homogenous, slightly bubbly, a little stiff, dry, tawny, \\
5 & 6 & homogeneous, slightly bubbly, stiff, dry, tawny, \\
5 & 7 & homogeneous, smooth, slightly stiff, dry, tawny, \\
5 & 8 & homogeneous, smooth, stiff, dry, tawny, \\
\hline
\end{tabular}

\footnotetext{
${ }^{1}$ HRSO : Hydroxylated rubber seed oil

${ }^{2}$ HMDI : Hexamethylene-1,6-diisocyanate
} 


\section{Characterization of polyurethane membrane}

Filtration processes was done by using mercury-contaminated water. The membrane surface area was $22.051 \mathrm{~cm}^{2}$ with a pressure of 20 bar and a filtration time of 20 minutes. The results of the flux and rejection factors can be seen in Table 2.

Rejection factor was obtained by calculating the concentration of mercury in the feed and permeate using atomic absorption spectrophotometry (AAS). Decoys are used in the form of mercury-contaminated

Table 2: Results of flux and rejection factor

\begin{tabular}{lccc}
\hline $\begin{array}{l}\text { HRSO } \\
\text { (ml) }\end{array}$ & $\begin{array}{c}\text { HMDI } \\
\text { (grams) }\end{array}$ & $\begin{array}{c}\text { Flux } \\
\text { L/m².h.bar }\end{array}$ & $\begin{array}{c}\text { rejection } \\
\text { factor \% }\end{array}$ \\
\hline 5 & 4 & 0,680 & $*$ \\
5 & 5 & 0,612 & $*$ \\
5 & 6 & 0,748 & $*$ \\
5 & 7 & 0,544 & 98,86 \\
5 & 8 & 0,680 & $*$ \\
\hline
\end{tabular}

*Not analyzed water with a mercury concentration of $0.0703 \mathrm{ppb}$, resulting permeate contains $0.0008 \mathrm{ppb}$ mercury. So that the resulting rejection factor was $98.86 \%$.

The results of the flux and rejection factors show that the polyurethane membrane can be used for mercury filtration from water. The membrane type was reverse osmosis membrane $(\mathrm{RO})$ base on a linear relationship between the pressure applied and the flux.

The FTIR spectrum of polyurethane membran is shown in Fig 4. The spectrum shows that the urethane bond had been formed. Urethane bond marked by the wavenumber $3308 \mathrm{~cm}^{-1}$ of $\mathrm{N}-\mathrm{H}$, wave number $1373 \mathrm{~cm}^{-1}$ of $\mathrm{CN}$, wave number 1739 $\mathrm{cm}^{-1}$ of $-\mathrm{C}=\mathrm{O}$ and the absence of $-\mathrm{NCO}$ absorption at wave number $2280 \mathrm{~cm}^{-1}$ for spectrum of polyurethane membrane.

Polyurethane membrane morphology was observed in cross sectional with magnification 100x and 500x as shown in Fig 5. The cross urethane

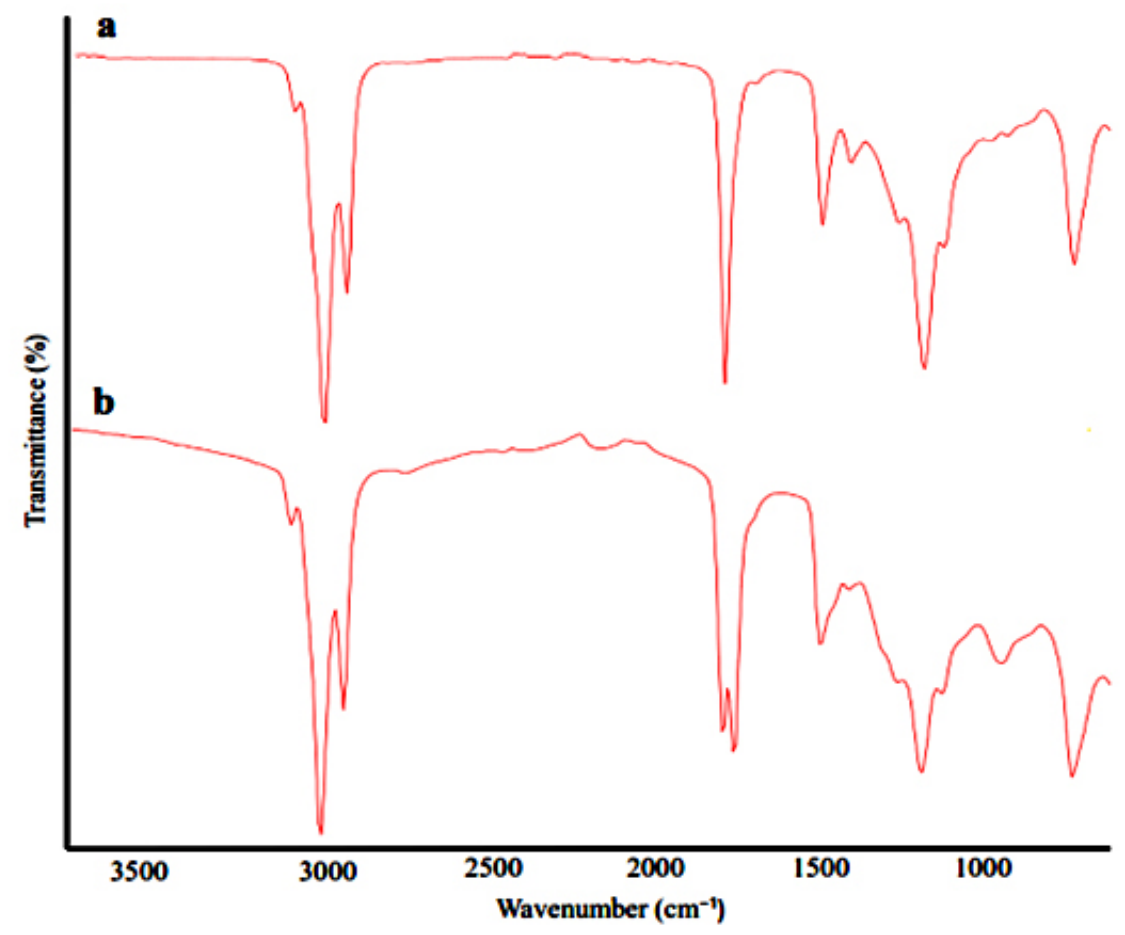

Fig. 2: FTIR spectra of (a) rubber seed oil and (b) hydroxylated rubber seed oil 
bond was formed on the membrane. The structure was randomly or amorphous. Irregularities made polyurethane membrane morphology becomes hollow.

There here two stages of decomposition of the membrane, which has characterized by weight loss at temperature $223 p \mathrm{C}$ and $386 \mathrm{p}$ C. The first decomposition was occurred at the weakest point in the structure of macromolecules.
The and decomposition happen urethane, bond, the thermostable ware aromatic groups and ester groups of the soft segment in the structure of macromolecules $8,9,10,11$. Polyurethane membrane weight loss of $50 \%$ at a temperature of $410 p \mathrm{C}$, weight loss of $90 \%$ at a temperature of $472 p$ C and residual $4.3 \%$ at a temperature of $500 p$ C. Thermal analysis using TGA showed two stages of decomposition as shown in Fig 6.<smiles>CCCCCC=CCC(O)C(O)CCCCCC(=O)OCCCCOC(=O)CCCCCCC=CCC(O)C(O)CCCCCCC</smiles>

Hydroxylated rubber seed oil

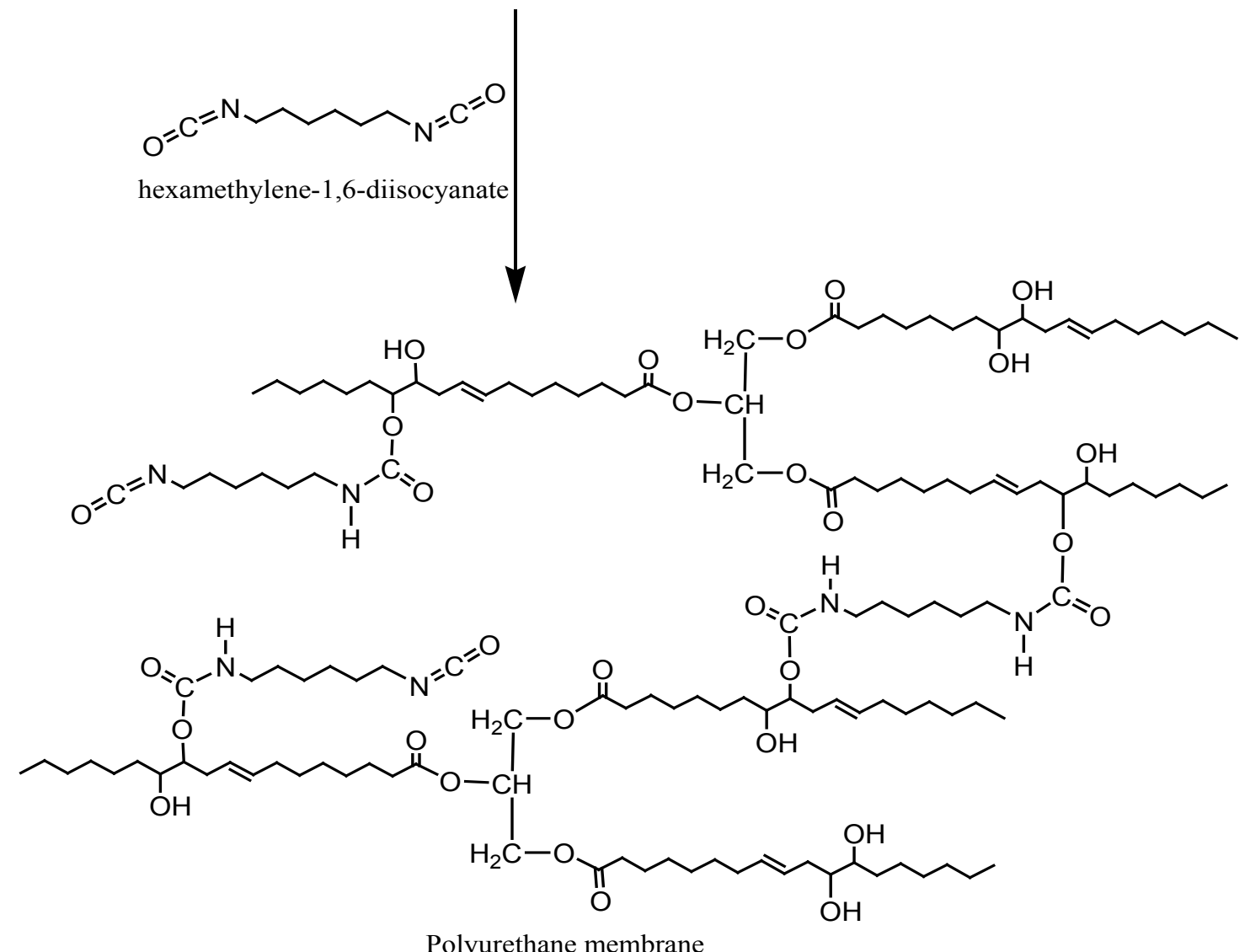

hexamethylene-1,6-diisocyanate

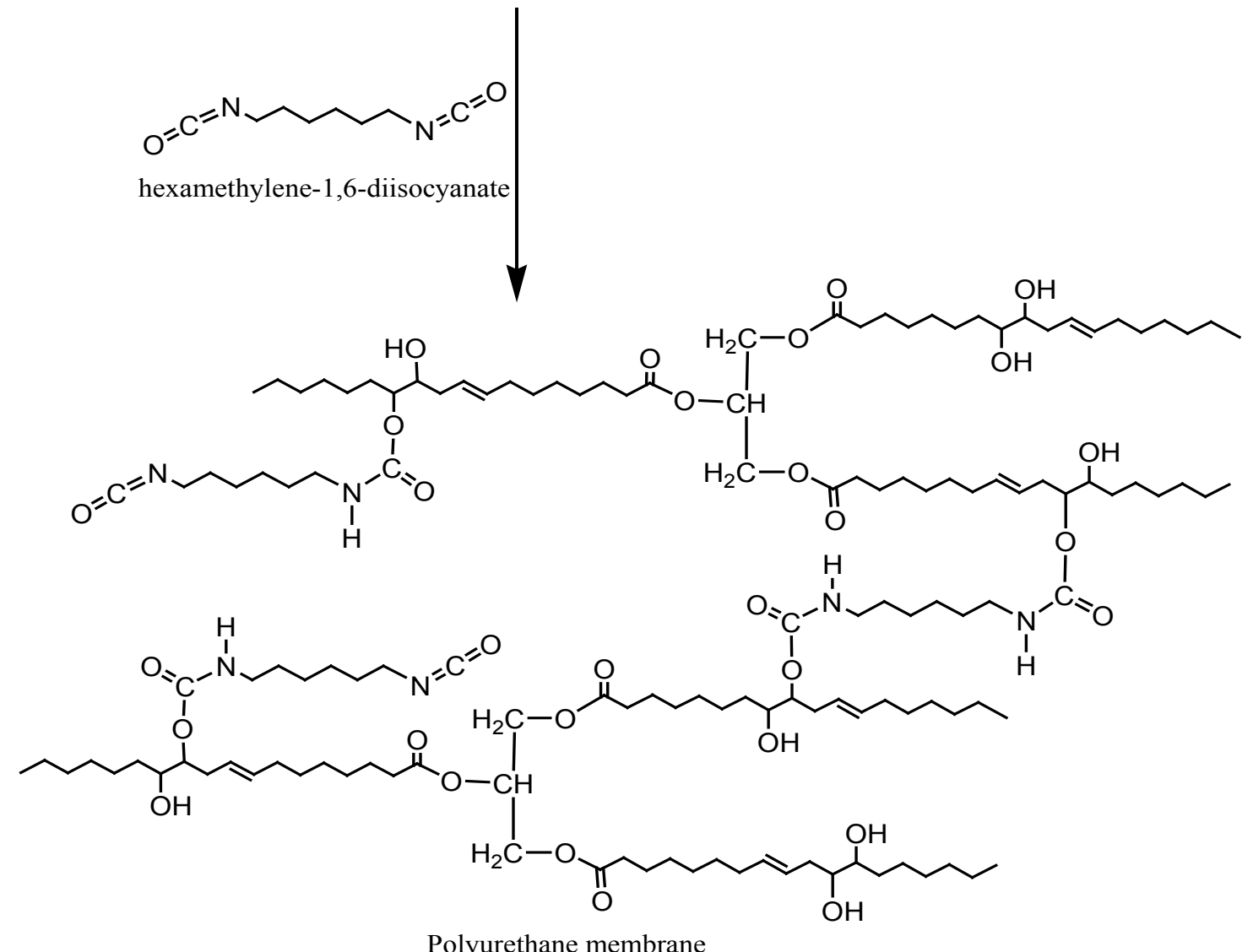

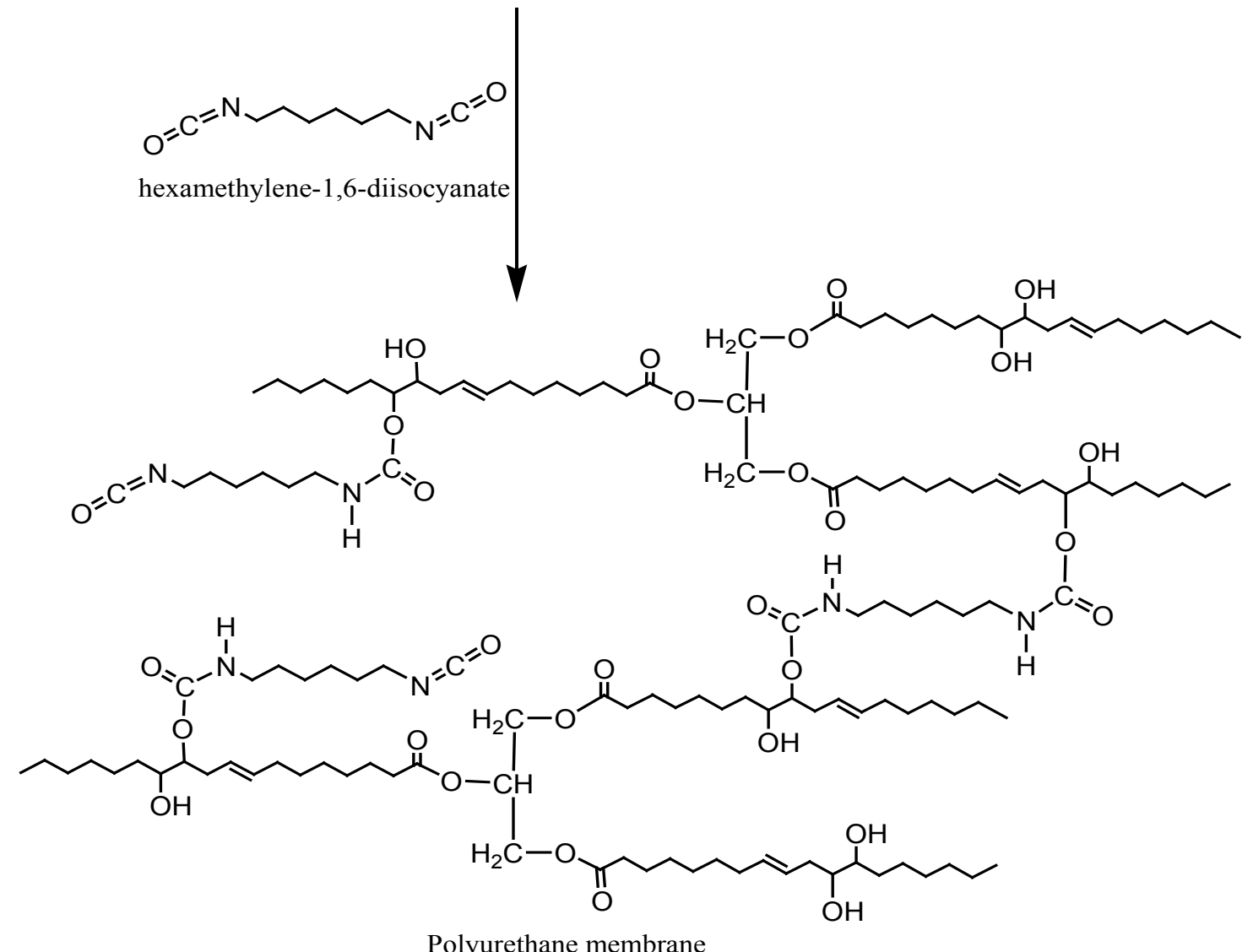<smiles>CCCCCCC=CCC(O)C(O)CCCCCC(=O)OCCCOC(=O)CCCCCCC=CCC(O)C(CCCCCC)OC(=O)N(CCCCCCN=C=O)NC(=O)CCCCCCC=CCC(O)C(O)CCCCCC</smiles>

Polyurethane membrane

Fig. 3: Suggested Hydroxylated reaction between linoleic acid and hexamethylene-1,6 diisocyanate 
Thermal analysis using DTA shows that the value $\mathrm{Tg}$ polyurethane membrane synthesized from hydroxylated rubber seed oil was $63^{\circ} \mathrm{C}$. As seen in Fig 7, the glass transition was an endothermic shift at baseline because of the heat capacity of the sample was inerease

Results of mechanical analysis showed that the polyurethane membrane was strong and elastic, with a tensile strength of $1.13 \mathrm{kgf} / \mathrm{mm}^{2}$ and elongation $215.36 \%$ Fig 8. Polyurethane membrane of rubber seed oil has more hydroxylated crosslinked (hard segment), so that when withdrawn are not prone to elongation, but the effect of the cross-linking of the membrane become stronger. Crosslinking result in higher tensile strength, so that the young modulus was also high.

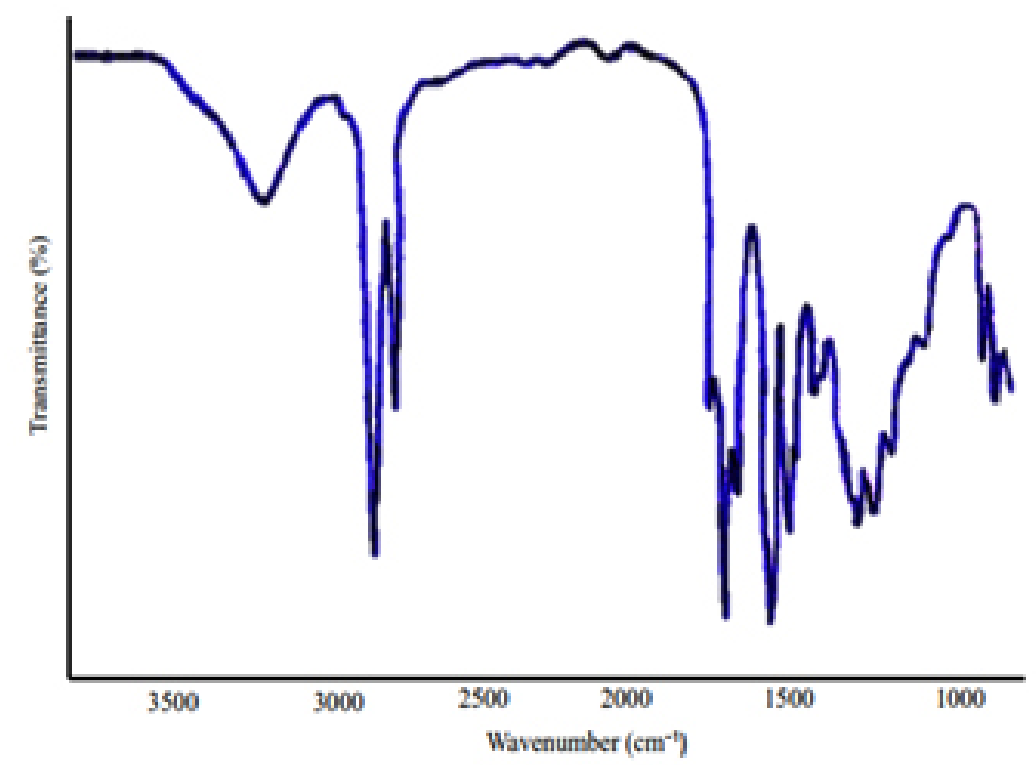

Fig. 4: FTIR spectra polyurethane membrane
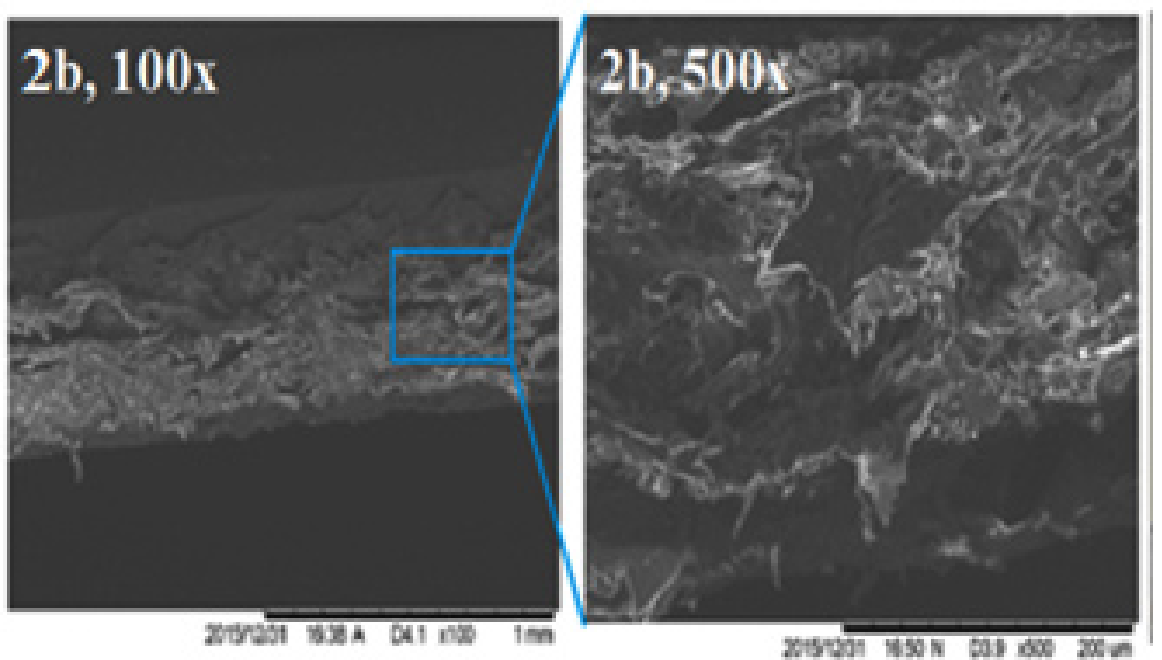

Fig. 5: SEM of polyurethane membrane with a magnification (2a) 100x and (2b) 500x 
Hydroxylation process can improve hydroxyl number $135.30 \%$ and decrease $73.91 \%$ of the iodine number. Increasing hydroxyl number indicates an increase in the -OH group in the rubber seed oil. Hydroxylated rubber seed oil was reacted with hexamethylene-1,6-diisocyanate to produce polyurethane membrane. The optimum composition of the polyurethane membrane synthesized from hydroxylated rubber seed oil and hexamethylene1,6-diisocyanate was 5:7 (v/w). The obtained membrane had properties of homogeneous, smooth, dry (not greasy), a little stiff, brownish yellow, flux of $0,544 \mathrm{~L} / \mathrm{m}^{2}$.h.bar and rejection factor of $98.86 \%$. The results of characterization of polyurethane membrane indicated the formation of a urethane bond at wave number $3308 \mathrm{~cm}^{-1}$, has two stages of decomposition at $223^{\circ} \mathrm{C}$ and $386^{\circ} \mathrm{C}$. The glass transition point $63^{\circ} \mathrm{C}$, tensile strength $1,13 \mathrm{kgf} / \mathrm{mm} 2$, elongation $215.36 \%$. The obtained polyurethane membrane can be classified on the type of reverse osmosis membrane.

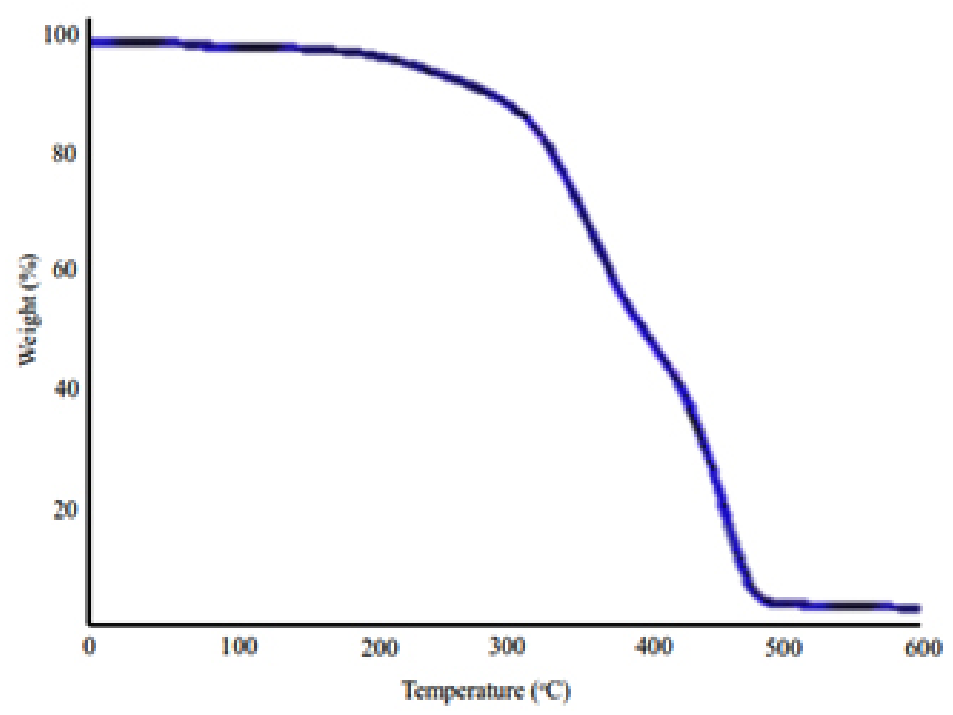

Fig. 6: TGA curves polyurethane membrane

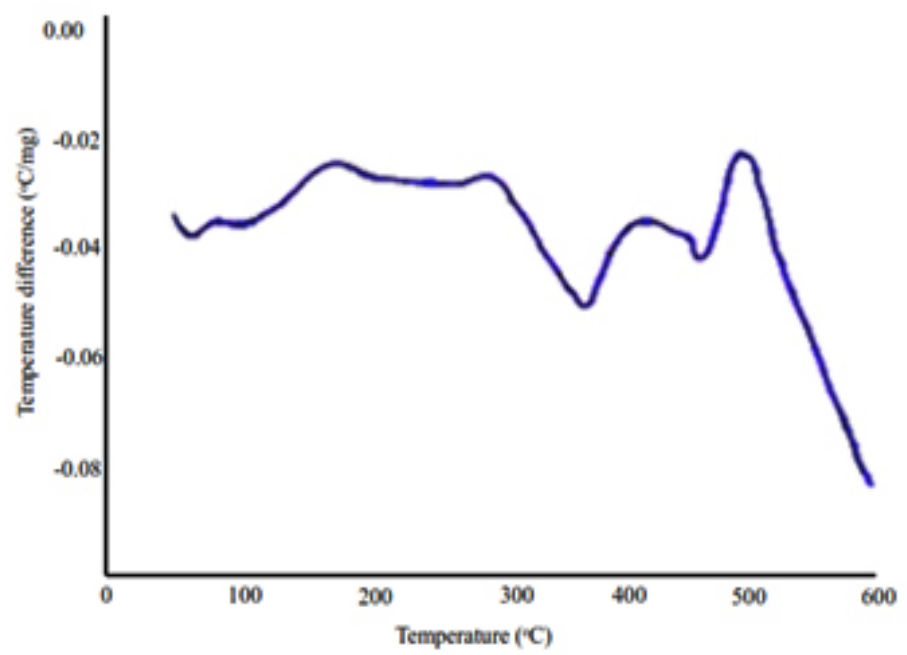

Fig. 7: DTA curve polyurethane membrane 


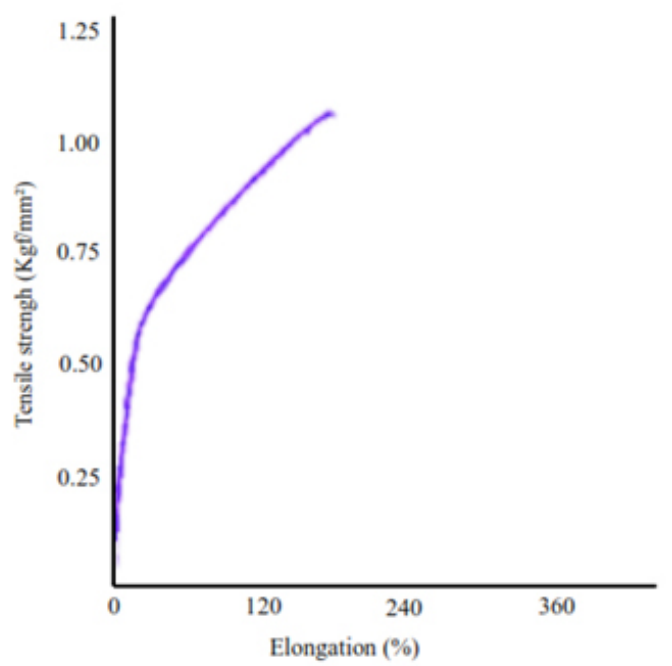

Fig. 8: Strain-stress curve polyurethane membrane

\section{ACKNOWLEDGEMENTS}

This research was supported by the Directorate of Research and Community Service Strengthening the Directorate General Research and development Ministry of Research, Technology and Higher Education (025/SP2H/LT/DRPM/II/2016).

\section{REFERENCES}

1. Sarma, S.; Dwi, S.; Hariyadi. J. Tek. Ind. Pert. 2011,19, 145-151.

2. Dwi, A. S.; Sperisa, D.; Nuryah, D.; Minyana, D. U. Ekui. 2010, 9, 11-15.

3. Achmad, W.; lindah, H.; Widayat. Mome. 2014, 10, 1-5.

4. Salfauqi, N.; Marlina; Saiful; Sitti, S. J.RKL. 2015, 10, 188-195.

5. Bakare, I. O.; Okieimen, F. E.; Pavithran, C.; Abdul Khalil, H. P. S.; Brahmakumar, M. Mater. and Des. 2010, 31, 4274-4280.

6. Manawer, A.; Deewan, A.; Eram, S.; Fahmina, Z.; Sharif, A. Arab. J. of Chem. 2014, 7, 469479.
7. Marlina. J. RKL. 2007, 6, 67-70.

8. Beauty, D.; Uday, K.; Manabendra, M.; Niranjan, K. Ind. Crop. and Prod. 2012, 44, 396-404.

9. Jose, H. S. A. J.; Daniel, A. B.; Alvaro, M.; Carlos, A. F.; Franco, D. R. A. J. Mater. Res. 2013, 16, 860-866.

10. Sariah, S.; Luqman, C. A.; Min, M. A.; Mek, Z. S.; Dayang, R. A. B.; Mahiran, B.; Emiliana, R. J. J. Ind. Crops. and Prod. 2015, 64, 194200.

11. Gurunathan, T.; Smita, M.; Sanjay, K. N. J. Prog. in Org. Coat. 2015, 80, 39-48. 